\title{
Microwave Surface Resistance of Plasma-Sprayed YBaCuO Thick Films on Large-Area Metallic Substrates
}
E. EZURA, K. ASANO, H. HAYANO, K. HOSOYAMA, S. INAGAKI, S. ISAGAWA, M. KABASAWA, Y. KOJIMA, S. KOSUGE, S. MITSUNOBU, T. MOMOSE, K. NAKADA, H. NAKANISHI, Y. SHIMBO, T. SHISHIDO, K. TACHIKAWA, T. TAKAHASHI and K. YOSHIHARA

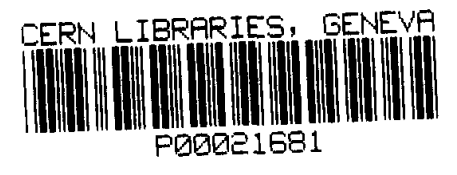

To be published in Jpn. J. Appl. Phys. 
National Laboratory for High Energy Physics, 1993

KEK Reports are available from:

Technical Information \& Library

National Laboratory for High Energy Physics

1-1 Oho, Tsukuba-shi

Ibaraki-ken, 305

JAPAN

Phone: $\quad 0298-64-1171$

Telex: $\quad 3652-534$ (Domestic)

(0)3652-534 (International)

Fax: $\quad$ 0298-64-4604

Cable: $\quad$ KEK OHO

E-mail: LIBRARY@JPNKEKVX (Bitnet Address)

library@kekvax.kek.jp (Internet Address) 


\section{Microwave Surface Resistance of Plasma-Sprayed YBaCuO Thick Films on Large-Area Metallic Substrates}

Eizi Ezura, Kiyomitsu Asano, Hitoshi Hayano, Kenji Hosoyama, Shigemi Inagaki, Shigeru Isagawa, Makoto Kabasawa ${ }^{1}$, Yuji Kojima, Shigeyoshi Kosuge ${ }^{1}$, Shinji Mitsunobu, Takashi Momose, Kiyokazu Nakada ${ }^{1}$ Hiroshi Nakanishi, Yukio Shimbo ${ }^{1}$, Toshio Shishido, Kyoji Tachikawa ${ }^{2}$, Tsuyoshi Takahashi and Kazuhiro Yoshihara ${ }^{3}$

KEK, National Laboratory for High Energy Physics, 1-1 Oho, Tsukuba, Ibaraki 305

${ }^{1}$ Materials and Processing Research Center, NKK Corporation, Kawasaki-ku, Kawasaki, Kanagawa 210

${ }^{2}$ Department of Material Science, Tokai University, Hiratsuka, Kanagawa 259-12

${ }^{3}$ National Research Institute for Metals, 1-2-1 Sengen, Tsukuba, Ibaraki 305

The microwave surface resistance of $\mathrm{YBaCuO}$ thick films was measured using a demountable copper cavity operated at $3 \mathrm{GHz}$ in the $\mathrm{TE}_{011}$ mode over a temperature range from $4.2 \mathrm{~K}$ to $300 \mathrm{~K}$. The films were deposited onto end plates and cylinder walls of silver substrates or nickel-buffered copper substrates by a low-pressure plasma-spraying technique combined with a melt-reaction method. The area of the end plate was $177 \mathrm{~cm}^{2}$ and that of the cylinder wall was $396 \mathrm{~cm}^{2}$. The surface resistance was obtained from the $Q$ values measured before and after substituting either the end plate or the cylinder wall for one covered with the film. The ratio of the surface resistance of the film to that of the copper was lower than 0.08 at $5.2 \mathrm{~K}$ and 0.65 at $77.3 \mathrm{~K}$ for the end plate and was 0.15 at $5.1 \mathrm{~K}$ and 1.91 at $77.3 \mathrm{~K}$ for the cylinder wall.

KEYWORDS: high- $T_{\mathrm{c}}$ superconductors, $\mathrm{YBaCuO}$ thick films, low-pressure plasma spraying, melt reaction, accelerator cavities, metallic substrates, microwave surface resistance, anomalous skin effect 


\section{Introduction}

The high- $T_{\mathrm{c}}$ superconductors open up many possibilities for practical applications in various fields. The development of synthesis techniques for high-quality materials will accelerate the progress of superconductive microwave applications. A key material property which determines their suitability for practical microwave applications is the surface resistance $R_{\mathbf{s}}$.

For planar microwave and electronic devices such as Josephson junctions and mixers, thin high- $T_{\mathrm{c}}$ films epitaxially grown on single-crystalline dielectric substrates give the lowest surface resistance. ${ }^{1-4)}$

Microwave devices such as antennas, filters, delay lines, couplers and resonators can be made on planar substrates by either thin or thick film processing techniques. However, for some microwave devices such as high- $Q$ cavities for frequency standards, the films must be deposited onto nonplanar substrates with relatively large area. Recently, melt-processed thick films of $\mathrm{YBaCuO}$ were fabricated on yttria-stabilized zirconia substrates and were shown to have very low surface resistance. $^{5-7)}$ Button and Alford ${ }^{7)}$ obtained $1.09 \mathrm{~m} \Omega$ at $77 \mathrm{~K}$ for a 5.66 $\mathrm{GHz}$ high- $T_{\mathrm{c}}$ cavity with a total surface area in excess of $230 \mathrm{~cm}^{2}$, which is an order of magnitude lower than the corresponding copper value.

For high-power accelerator cavities, not only must high- $T_{\mathrm{c}}$ films be deposited onto large-area substrates of complex shape, but the use of metallic substrates of high thermal conductivity is also essential. As the thermal conductivity of high- $T_{\mathrm{c}}$ materials is rather low, ${ }^{8)}$ heat must be released to keep the film in a superconducting state even under a high field. Bohn et al. ${ }^{9)}$ fabricated bismuthbased thick films $(80 \mu \mathrm{m})$ by applying high-viscocity slurries on large-area silver substrates. The sample with surface area of $182 \mathrm{~cm}^{2}$ had surface resistance of 6.7 $\mathrm{m} \Omega$ and $9.0 \mathrm{~m} \Omega$ at $2.65 \mathrm{GHz}$ and $3.65 \mathrm{GHz}$, respectively, at $4.2 \mathrm{~K} .^{9)}$ Thalliumbased thick films $(15 \mu \mathrm{m})$ were fabricated by magnetron sputtering onto $\mathrm{BaF}_{2}$ buffered silver-based substrates with surface area of $5 \mathrm{~cm}^{2}$. The obtained surface resistance was $6.9 \pm 2 \mathrm{~m} \Omega$ at $11.3 \mathrm{~K}$ and $30.2 \pm 1 \mathrm{~m} \Omega$ at $77 \mathrm{~K}$ at a frequency of 22 GHz. ${ }^{10)}$ Furthermore, Cooke et al. also showed that deposition onto unoriented silver substrates yielded unoriented films with $R_{\mathrm{s}}$ value of $8.2 \mathrm{~m} \Omega$ at $10.6 \mathrm{~K}$ and $33.6 \mathrm{~m} \Omega$ at $77 \mathrm{~K}$, and that deposition onto oriented silver substrates yielded oriented films with values of $12.6 \mathrm{~m} \Omega$ at $11.2 \mathrm{~K}$ and $14.6 \mathrm{~m} \Omega$ at $77 \mathrm{~K}$ at a frequency of $18 \mathrm{GHz} .{ }^{11)}$ An electrophoretic technique was developed to deposit yttrium-based 
thick films $(10-20 \mu \mathrm{m})$ on silver substrates. ${ }^{12)}$ A strong magnetic field of $8 \mathrm{~T}$ was applied to the suspension to orient the c-axis perpendicular to the substrates. The surface resistance of the sample with the area of $4.5 \mathrm{~cm}^{2}$ measured at $21.5 \mathrm{GHz}$ was $18 \pm 3 \mathrm{~m} \Omega$ at $77 \mathrm{~K}$ and less than $3 \mathrm{~m} \Omega$ at $4.2 \mathrm{~K}^{13,14)}$

Plasma spraying can be applied to form high- $T_{\mathrm{c}}$ films on large-area substrates with complicated shapes. Here we deposited $\mathrm{YBaCuO}$ thick films by a lowpressure plasma-spraying technique. ${ }^{15,16)}$ In comparison with plasma spraying in open air, ${ }^{17-19)}$ it gives a higher density and a better quality of films in a controlled spraying atmosphere. The $\mathrm{YBaCuO}$ films prepared by plasma spraying, however, contain some insulating or semiconducting phases such as $\mathrm{BaCuO}_{2}, \mathrm{Y}_{2} \mathrm{BaCuO}_{5}$ or $\mathrm{CuO}$, which are precipitated due to the decomposition of $\mathrm{YBa}_{2} \mathrm{Cu}_{3} \mathrm{O}_{7-x}$ during the melting process. ${ }^{15}$ ) This second-phase intrusion cannot be avoided by simply optimizing the spraying or the postannealing conditions. We previously showed ${ }^{20,21)}$ that the melt-reaction method reduced the second-phase intrusion and made the $\mathrm{YBa}_{2} \mathrm{Cu}_{3} \mathrm{O}_{7-x}$ layer denser and more uniform.

We measured the microwave surface resistance of the film fabricated by this method. A cylindrical cavity operated at $3 \mathrm{GHz}$ in the $\mathrm{TE}_{011}$ mode was employed. The frequency was chosen from the consideration that the fabrication of highquality films becomes more difficult as the size of the cavity increases, whereas the highest frequency for superconducting acccelerator cavities envisaged for the next generation is around $3 \mathrm{GHz}$. The area of the flat plate was $177 \mathrm{~cm}^{2}$ and that of the cylinder was $396 \mathrm{~cm}^{2}$. The substrates were either silver or nickel-plated copper. In this report, we describe the sample preparation by the plasma-spraying technique, the method of surface resistance measurement and the results.

\section{$2 \quad$ Fabrication of Films}

Superconductive films of $\mathrm{YBaCuO}$, the thickness of which is around $30-50 \mu \mathrm{m}$, were prepared on silver substrates and copper substrates by a low-pressure plasmaspraying and a melt-reaction method. ${ }^{20,21)}$ For copper substrates, nickel was first electroplated to form a buffer layer of about $20-40 \mu \mathrm{m}$ thickness, which prevents diffusion of copper into $\mathrm{YBaCuO}$ films. ${ }^{15,22)}$ On the other hand, $\mathrm{YBaCuO}$ powder was directly sprayed onto silver substrates. The schematic drawing of the lowpressure plasma-spraying apparatus is shown elsewhere. ${ }^{15)}$ The powder supplied to the plasma jet was melted and blasted onto the substrates to form the film. 
The pressure of the chamber was maintained at around $8000 \mathrm{~Pa}$ of oxygen. The feedstock powder was prepared by the solid-state reaction method. Mixed powder of $\mathrm{Y}_{2} \mathrm{O}_{3}, \mathrm{BaCO}_{3}$ and $\mathrm{CuO}$ with nominal composition of $\mathrm{Y}: \mathrm{Ba}: \mathrm{Cu}=3: 3: 4$ (powder I) and $\mathrm{Y}: \mathrm{Ba}: \mathrm{Cu}=1: 13: 26$ (powder II) was calcined at $950^{\circ} \mathrm{C}$ and pulverized. The size of the particles ranged from 26 to $44 \mu \mathrm{m}$.

The melt reaction is a combined process of the flux method and the peritectic reaction method. The melt composed of $\mathrm{YO}_{1.5}$ and excessive $\mathrm{BaO}$ and $\mathrm{CuO}$ is in equilibrium with $\mathrm{YBa}_{2} \mathrm{Cu}_{3} \mathrm{O}_{7-x}$ and acts as a flux to enhance the grain growth of $\mathrm{YBa}_{2} \mathrm{Cu}_{3} \mathrm{O}_{7-x}$. The melt-reaction method consisted of two stages. First, layer I, composed of a mixture of $\mathrm{YBa}_{2} \mathrm{Cu}_{3} \mathrm{O}_{7-x}$ and $\mathrm{Y}_{2} \mathrm{BaCuO}_{5}$, is formed using powder I on the substrates by the plasma spraying. Subsequently, layer II, composed of a mixture of $\mathrm{BaCuO}_{2}, \mathrm{CuO}$ and $\mathrm{YBa}_{2} \mathrm{Cu}_{3} \mathrm{O}_{7-x}$, is overlayed using powder II on layer I by the second plasma-spraying process. The thicknesses of layer $\mathrm{I}$ and layer II were $150 \mu \mathrm{m}$ and $50 \mu \mathrm{m}$, respectively, in these experiments. In the case of the nickel-buffered copper substrate, the double-layered film is annealed in oxygen at $930^{\circ} \mathrm{C}$ to $970^{\circ} \mathrm{C}$, where layer II melts. The molten oxide diffuses into layer I and acts as a flux which enhances the grain growth of $\mathrm{YBa}_{2} \mathrm{Cu}_{3} \mathrm{O}_{7-x}$ in layer $\mathrm{I}$. Simultaneously, the excess flux reacts with $\mathrm{Y}_{2} \mathrm{BaCuO}_{5}$ to form $\mathrm{YBa}_{2} \mathrm{Cu}_{3} \mathrm{O}_{7-x}{ }^{21}$ ) These reactions yield a dense and uniform $\mathrm{YBa}_{2} \mathrm{Cu}_{3} \mathrm{O}_{7-x}$ layer with thickness of about $40 \mu \mathrm{m}$. The excess flux remaining on the reacted layer is removed by polishing with emery paper. In the case of the silver substrate, the double-layered film is annealed in an atmosphere of $7.7 \%$ oxygen and $92.3 \%$ argon at $900^{\circ} \mathrm{C}$ for $1 \mathrm{~h}$ with a successive heat treatment in $100 \%$ oxygen at $700^{\circ} \mathrm{C}$ for $4 \mathrm{~h}$.

The skin depth $\delta$ is equal to the magnetic field penetration depth $\lambda$ if the temperature is not very close to the critical temperature $T_{c}{ }^{23)}$ For single crystals of $\mathrm{YBaCuO}, \lambda$ at $77 \mathrm{~K}$ is about $0.21 \mu \mathrm{m}$ in the a-b plane and about $1.0 \mu \mathrm{m}$ in the $c$ direction. ${ }^{24,25)}$ The film thickness of over $30 \mu \mathrm{m}$ therefore ensures that the microwave field does not penetrate into the nonsuperconducting layer to produce additional microwave losses. The microstructure of the oxide layer after annealing was studied with the use of an optical microscope, a scanning electron microscope (SEM) and an energy dispersive X-ray spectroscope (EDX). Figure 1 shows a polarized light micrograph of $\mathrm{YBa}_{2} \mathrm{Cu}_{3} \mathrm{O}_{7-x}$. Most of the rectangular grains were about $20 \mu \mathrm{m}$ long and $5 \mu \mathrm{m}$ wide. Figure 2(a) is a SEM image of a cross section between the reacted layer and layer I. Figure 2(b) shows the EDX images of the upper middle sextant of Fig. 2(a), showing the distribution of $\mathrm{Y}, \mathrm{Ba}$ and $\mathrm{Cu}$. 
Element analysis revealed that the reacted layer mainly consisted of $\mathrm{YBa}_{2} \mathrm{Cu}_{3} \mathrm{O}_{7-x}$ and contained a small amount of $\mathrm{Y}_{2} \mathrm{BaCuO}_{5}$ and $\mathrm{CuO}$ grains. The chemical compositions of several points are denoted to the right of Fig. 2(a). The transport critical current density of the superconducting film exceeded $2 \times 10^{7} \mathrm{~A} / \mathrm{m}^{2}$ at 77 $K$. This value is much higher than that of the films prepared by conventional plasma spraying.

\section{Experimental Setup}

A cylindrical cavity resonating at $3 \mathrm{GHz}$ in the $\mathrm{TE}_{011}$ mode is used for measuring the surface resistance of the superconductive films. The dimensions of the cavity are $150 \mathrm{~mm}$ diameter and $84 \mathrm{~mm}$ length. The theoretical values of the copper cavity are as follows. The frequency and the skin depth are $3.02 \mathrm{GHz}$ and 1.20 $\mu \mathrm{m}$ for both $\mathrm{TE}_{011}$ and $\mathrm{TM}_{111}$ modes; the $Q$ value is $4.90 \times 10^{4}$ and $2.24 \times 10^{4}$ for the above modes at room temperature $\left(\rho=1.72 \times 10^{-8} \Omega \mathrm{m}\right)$. The host cavity was machined out of oxygen-free high-conductivity copper (OFHC) blocks. As shown in Fig. 3, it consists of a top plate, a cylinder wall and a bottom plate. Indium wire of $1.0 \mathrm{~mm}$ in diameter was used between the end plates and the cylinder wall for vacuum sealing and electrical contact. The bottom plate has two if and one vacuum port. Microwaves are loop-coupled into and out of the cavity through two $50 \Omega$ coaxial lines. The coupling to the cavity can be varied by moving the line along the axis of the cavity with a fine driving mechanism. The movable length of the line is $25 \mathrm{~mm}$, which enables critical and weak coupling over a wide range of the cavity quality factor $\left(Q_{0}=10^{3}-10^{10}\right)$. The central pumping hole in the bottom plate contributes to breaking the degeneracy between the $\mathrm{TE}_{011}$ and $\mathrm{TM}_{111}$ modes. The hole perturbs the field distribution of the $\mathrm{TM}_{111}$ mode to decrease its frequency, whereas it hardly affects the $\mathrm{TE}_{011}$ mode. With the pumping hole of $15 \mathrm{~mm}$ in diameter the center frequencies of the $\mathrm{TE}_{011}$ and $\mathrm{TM}_{111}$ modes become $3.0217 \mathrm{GHz}$ and $3.0182 \mathrm{GHz}$, respectively, at room temperature. The separation of $3.5 \mathrm{MHz}$ is sufficiently wide compared to the $3 \mathrm{~dB}$ bandwidth of the $\mathrm{TE}_{011}$ mode resonance.

The cavity was evacuated with a $10 \mathrm{l} / \mathrm{s}$ ion pump and a $50 \mathrm{l} / \mathrm{s}$ turbomolecular pump. Typical pressure in the unbaked cavity was $10^{-5}-10^{-6} \mathrm{~Pa}$ before cooling. The temperature of the cavity was monitored with thermocouple sensors (Kp vs $\mathrm{Au}_{7} \mathrm{Fe}$ ) mounted on the top and bottom outer surfaces of the cavity. The cavity 
was preliminarily cooled to $77 \mathrm{~K}$ with liquid nitrogen. After liquid nitrogen was removed from the cryostat, the cavity was cooled to $4.2 \mathrm{~K}$ with liquid helium. The measurement was started from this temperature. The cavity was warmed up sufficiently slowly to maintain approximate thermal equilibrium. It was not actually necessary to pour liquid nitrogen into the outer vessel of the cryostat to allow the temprerature to rise to $300 \mathrm{~K}$. The measurement continued at a constant temperature interval, and the temperature range from $4.2 \mathrm{~K}$ to $300 \mathrm{~K}$ was covered within about three days. The apparatus used were a network analyzer, a 30-channel vacuum and temperature monitor and two sets of a coupler driver and position monitor. These were linked to a personal computer through GP-IB.

\section{Measurement of the Surface Resistance}

The surface resistance is obtained through the $Q$ value of a cavity excited in the $\mathrm{TE}_{011}$ mode. This mode has no current traversing the contact between the end plate and the cylinder wall. Furthermore, as this mode has no electric field on the cavity surface, it causes no electron loading and enables measurement at high rf field levels.

A network analyzer (HP $8720 \mathrm{~A}$ ) determines the resonant peak and half-power points from the $S_{21}$ coefficient, which leads to the loaded quality factor $Q_{\mathrm{L}}$. From the $S_{11}$ and $S_{22}$ coefficients of the two coupling ports, the coupling factors $\beta_{1}$ and $\beta_{2}$ are calculated. The values of $Q_{0}$ are then obtained from

$$
Q_{0}=Q_{\mathrm{L}}\left(1+\beta_{1}+\beta_{2}\right)
$$

Initially the unloaded quality factor $Q_{0, \mathrm{C}}(T)$ of the copper cavity is measured as a function of temperature $T$, and the surface resistance of copper $R_{\mathrm{s}, \mathrm{C}}(T)$ is calculated. Then, either the top plate or the cylinder wall is replaced by one covered with a superconductive film, and the unloaded quality factor $Q_{0, \mathrm{~S}}(T)$ is measured. In terms of these unloaded quality factors and the geometrical factors $k$ defined below, the surface resistance $R_{\mathrm{s}}(T)$ of the film is given by

$$
R_{\mathrm{s}}(T) / R_{\mathrm{s}, \mathrm{C}}(T)=k\left(Q_{0, \mathrm{C}}(T) / Q_{0, \mathrm{~S}}(T)-1\right)+1
$$

The geometrical factor $k$ of the end plate or the cylinder is defined as

$$
k=\int_{\mathrm{C}} H_{\|}^{2} d S / \int_{\mathrm{S}} H_{\|}^{2} d S
$$


where $H_{\|}$is the magnetic field parallel to the surface, and the numerator is integrated over the whole surface of the cavity and the denominator is integrated over the surface covered with a superconductive film. For a cylindrical cavity operating in the $\mathrm{TE}_{01 n}$ mode, $k$ is expressed as

$$
k=2+(l / a)^{3}\left(q_{01}^{\prime} / n \pi\right)^{2}
$$

for an end plate and

$$
k=1+(2 a / l)\left(n \pi a / q_{01}^{\prime} l\right)^{2}
$$

for a cylinder wall. $q_{01}^{\prime}$ is the first root of Bessel's equation $J_{0}^{\prime}(x)=0$, and $a$ and $l$ are the radius and length of the cavity.

Now we discuss the error of measurement, where part of the copper cavity is replaced by a superconducting material. As the surface resistance of the material becomes much smaller than that of the copper, the relative error increases because of the difficulty in seperating the sample loss from the dominant loss of copper. Differentiation of $R_{\mathrm{s}}$ in eq.(2) with respect to $Q_{0, \mathrm{~S}}$ and additional operations lead to

$$
\left(d R_{\mathrm{s}} / R_{\mathrm{s}}\right) /\left(d Q_{0, \mathrm{~s}} / Q_{0, \mathrm{~s}}\right)=-\left[\left(R_{\mathrm{s}} / R_{\mathrm{s}, \mathrm{C}}\right)+(k-1)\right] /\left(R_{\mathrm{s}} / R_{\mathrm{s}, \mathrm{C}}\right),
$$

where $(T)$ is omitted for brevity and $R_{\mathrm{s}, \mathrm{C}}$ and $Q_{0, \mathrm{C}}$ are constant. Figure 4 shows the numerical values of $\left(d R_{\mathrm{s}} / R_{\mathrm{s}}\right) /\left(d Q_{0, \mathrm{~S}} / Q_{0, \mathrm{~S}}\right)$ as a function of $R_{\mathrm{s}} / R_{\mathrm{s}, \mathrm{C}}$ for $k=$ 4.09 (an end plate), 1.96 (a cylinder wall) and 1.32 (the combination of an end plate and a cylinder wall). The error of $Q$ measurement is around $1 \%$. The figure shows that a change of $1 \%$ in $\left(d Q_{0, \mathrm{~S}} / Q_{0, \mathrm{~S}}\right)$ corresponds to about $30 \%$ change in $d R_{\mathrm{s}} / R_{\mathrm{s}}$ at $R_{\mathrm{s}} / R_{\mathrm{s}, \mathrm{C}}=0.1$, and about $100 \%$ change in $d R_{\mathrm{s}} / R_{\mathrm{s}}$ at $R_{\mathrm{s}} / R_{\mathrm{s}, \mathrm{C}}=0.03$ for the end plate. This suggests the necessity of an entire superconducting cavity if we require an accurate value of $R_{\mathrm{s}}$ in a region where $R_{\mathrm{s}} \ll R_{\mathrm{s}, \mathrm{C}}$. Another way of improving the accuracy is to measure a mode with a higher frequency. At low temperature the surface resistance of a high- $T_{\mathrm{c}}$ film is approximately proportional to $f^{2}$ at low field, while $R_{\mathrm{s}, \mathrm{C}}$ changes with frequency as $f^{0.6-0.7}$. Therefore, $R_{\mathrm{s}} / R_{\mathrm{s}, \mathrm{C}}$ increases with frequency, making the measurement error smaller.

\section{Experimental Results and Discussion}

In the present experiments, the input power to the cavity is $-14.2 \mathrm{dBm}$, where $-4.2 \mathrm{dBm}$ is caused by the attenuation of the cable connecting the network analyzer and the cavity. From the coupling factor and $Q_{0}$ of the cavity, the magnetic 
field at the cavity surface is estimated to be lower than $0.7 \mathrm{~A} / \mathrm{m}$ at $4.2 \mathrm{~K}$ and lower than $0.19 \mathrm{~A} / \mathrm{m}$ at $77 \mathrm{~K}$. It is well known that the rf losses observed in high- $T_{\mathrm{c}}$ materials are explained by a model of Josephson coupling between the superconducting grains. ${ }^{26,27)}$ At fields exceeding the lower critical field of the junction $H_{\mathrm{c} 1 \mathrm{~J}}$, the rf magnetic flux penetrates into the Josephson medium and causes rf loss proportional to the magnetic field intensity. ${ }^{28)}$ We confirmed that the surface resistance is independent of the excitation around this field level and that $H_{\mathrm{c} 1 \mathrm{~J}}$ is located at a higher field.

\subsection{Surface resistance of copper}

Figure 5 shows the measured surface resistance $R_{\mathrm{s}, \mathrm{C}}$ of the entire copper cavity as a function of temperature. The measured resistivity $\rho$ of pure copper is reported in ref. 29. With that value and the permeability $\mu$, the surface resistance calculated as

$$
R_{\mathrm{s}}=\rho / \delta=(\omega \rho \mu / 2)^{1 / 2}
$$

is plotted in Fig. 5 as well. The measured value at $299.8 \mathrm{~K}$ is $15.7 \mathrm{~m} \Omega$, which is $9.9 \%$ higher than that of the theoretical value $14.3 \mathrm{~m} \Omega$. This $R_{\mathrm{s}, \mathrm{C}}$ vs $T$ curve is fitted by a polynomial of order nine, and is used for the derivation of the surface resistance of high $-T_{\mathrm{c}}$ films. In the temperature region below $50 \mathrm{~K}$, the residual resistance and/or the anomalous skin effect becomes dominant and the figure suggests that we may assume a constant value for $11.2-4.2 \mathrm{~K}$, a region in which measurements were not made. We adopt $R s=5.11 \mathrm{~m} \Omega$, the average of the ten lowest values.

\subsection{Surface resistance of $\mathrm{YBaCuO}$ films}

We have prepared seven samples so far: a $\mathrm{YBaCuO}$ film on a silver end plate (labelled $\mathrm{YBaCuO} / \mathrm{Ag}$-e), four $\mathrm{YBaCuO}$ films on copper end plates ( $\mathrm{YBaCuO} / \mathrm{Cu}$ e1 $\sim \mathrm{YBaCuO} / \mathrm{Cu}-\mathrm{e} 4$ ), and two $\mathrm{YBaCuO}$ films on copper cylinder walls ( $\mathrm{YBaCuO} / \mathrm{Cu}$ $\mathrm{c} 1$ and $\mathrm{YBaCuO} / \mathrm{Cu}-\mathrm{c} 2)$.

The surface resistance and unloaded $Q$ value of $\mathrm{YBaCuO} / \mathrm{Ag}$-e are shown in Fig. 6, as well as those for the entire copper cavity. $R_{\mathrm{s}}$ is calculated by eq.(2) using $Q_{0, \mathrm{~S}}, Q_{0, \mathrm{C}}$ and $R_{\mathrm{s}, \mathrm{C}}$. The surface resistance of the sample became equal to that of copper at $79 \mathrm{~K}$, and less than $0.9 \mathrm{~m} \Omega$ at $50 \mathrm{~K}$. The value near the liquid helium temperature was $0.1-0.2 \mathrm{~m} \Omega$. For convenience of comparison, we define 
the left side of eq.(2) as the normalized surface resistance $r_{\mathrm{n}}$, i.e.,

$$
r_{\mathrm{n}}=r_{\mathrm{n}}(T) \equiv R_{\mathrm{s}}(T) / R_{\mathrm{s}, \mathrm{C}}(T)
$$

This definition can be extended to include the frequency dependence. The normalized resistance of this sample is shown in Fig. 8 and the following several figures. In Fig. $7, d r_{n} / d T$ is plotted as a function of $T$. The sharp peak at $91.8 \mathrm{~K}$ can be defined as the onset of the transition. Although a high- $T_{\mathrm{c}}$ film on the silver substrate gave a rather promising result, we chose copper for substrates because copper is more suitable than silver as a basal metal for accelerator cavities in the points of mechanical strength and melting point. Copper is also preferable from the economical point of view.

The normalized surface resistance versus temperature for $\mathrm{YBaCuO} / \mathrm{Cu}$-el down to the liquid helium temperature is shown in Fig. 8, where $Q_{0}$ changed from $1.63 \times 10^{5}$ at $5.1 \mathrm{~K}$ to $1.02 \times 10^{4}$ at $118.5 \mathrm{~K}$. The surface resistance of the sample was $1.8 \mathrm{~m} \Omega$ at $5.1 \mathrm{~K}$. The transition temperature was $92 \mathrm{~K}$ and the surface resistance of the sample became smaller than that of copper below $80 \mathrm{~K}$. The surface resistance of $\mathrm{YBaCuO} / \mathrm{Cu}-\mathrm{el}$ dropped more sharply and reached a smaller value at $77 \mathrm{~K}$ than that of $\mathrm{YBaCuO} / \mathrm{Ag}$-e. However, the sample exhibited a bending point at $70 \mathrm{~K}$, where the sharp decrease of the normalized surface resistance became approximately constant, indicating that the sample had a rather large residual resistance. The value of $T_{\mathrm{c}}$ agreed well with the onset temperature obtained from dc resistivity measurement. In the case of $\mathrm{YBaCuO} / \mathrm{Cu}-\mathrm{e} 2$, the behavior of $Q_{0}$ was peculiar and nonreproducible. From the beginning of measurement at the liquid helium temperature, the $Q_{0}$ value was only $12 \%$ higher than that of copper. It gradually decreased until $60 \mathrm{~K}$, where it suddenly increased by $20 \%$. It remained near this value until $70 \mathrm{~K}$, then gradually decreased. Since we could not detect any hardware or software problem, we repeated the measurement after twenty-five hours. This time the $Q_{0}$ values were degraded to $67 \%$ of the first value at $4.8 \mathrm{~K}$, but again increased slightly at $55 \mathrm{~K}$ and followed the same trajectory as the first value above $76 \mathrm{~K}$. As shown in Fig. 9, the transition temperature of the $\mathrm{YBaCuO} / \mathrm{Cu}$ e3 sample was almost the same as that of the $\mathrm{YBaCuO} / \mathrm{Ag}$-e sample. At $81 \mathrm{~K}$ the surface resistance became equal to that of the copper as well. Below $50 \mathrm{~K}, r_{\mathbf{n}}$ became less than one-tenth. The normalized surface resistance from $85 \mathrm{~K}$ to $60 \mathrm{~K}$ was better than that of $\mathrm{YBACuO} / \mathrm{Ag}-\mathrm{e}$. In the case of $\mathrm{YBaCuO} / \mathrm{Cu}-\mathrm{e} 4$, the onset transition temperature was less sharp than in $\mathrm{YBaCuO} / \mathrm{Ag}-\mathrm{e}$, and above $67 \mathrm{~K}$, 
the surface resistance was higher than that of copper. Later the sample was rinsed in acetone bath in an ultrasonic washer to remove the residuals generated in the polishing process. However, this treatment yielded no apparent deviation from the initial measurement. Among the four $\mathrm{YBaCuO}$ films on copper end plates, the fourth was annealed in a different furnace from the others, but we endeavored to maintain the same conditions for all samples. As we achieve good reproducibility in fabricating approximately 1-cm-square samples, the dissimilar of properties of the present samples can be attributed mostly to their size. For larger samples, it is more difficult to maintain the uniformity and stability of temperature and gaseous atmosphere during the heat treatment. A lower temperature or higher oxygen pressure causes an inadequate reaction and leaves residual flux between the grain boundaries.

The surface resistance of $\mathrm{YBaCuO} / \mathrm{Cu}-\mathrm{cl}$ decreased from $385 \mathrm{~m} \Omega$ at $T_{\mathrm{c}}(91.7 \mathrm{~K})$ to $1.2 \mathrm{~m} \Omega$ at $5.1 \mathrm{~K}$ (Fig. 10). Although the normalized surface resistance was lower than 1.0 below $69.2 \mathrm{~K}$, the absolute value was not as low as those obtained for the end-plate samples. In the case of the second cylinder sample, $\mathrm{YBaCuO} / \mathrm{Cu}-\mathrm{c} 2$, the resonance curve was so broad that we could not seperate the $\mathrm{TE}_{011}$ mode from the $\mathrm{TM}_{111}$ mode. However, the onset of the transition was clearly recognized. To fabricate a better-quality film on the inner surface of the cylinder, the uniformity of spraying and temperature distribution of the cylinder must be improved in the spray process, as well as the uniformity in the heat treatment process.

The best sample, $\mathrm{YBaCuO} / \mathrm{Cu}-\mathrm{e} 3$, showed a sharp decrease of surface resistance below the onset of the transition with a smaller surface resistance than that of copper at $77.3 \mathrm{~K}$. It had a smaller resistance than that of $\mathrm{YBaCuO} / \mathrm{Ag}$-e below $85 \mathrm{~K}$, and the surface resistance was less than $0.4 \mathrm{~m} \Omega$ at $5.2 \mathrm{~K}$, at least one order of magnitude better than that of copper at the same temperature.

\section{Conclusions}

We have demonstrated that the low-pressure plasma-spraying technique allows fabrication of $\mathrm{YBaCuO}$ thick films on copper and silver substrates with large areas comparable to the size of an actual accelerator cavity. The surface resistance was measured at the frequency of $3 \mathrm{GHz}$ using a demountable copper cavity over the temperature range from liquid helium to room temperature. The best film on the 
end plate with the area of $177 \mathrm{~cm}^{2}$ had the surface resistance of $4-8 \%$ of that of copper at $5.2 \mathrm{~K}$ and about $65 \%$ at $77.3 \mathrm{~K}$. The surface resistance of the film on the cylinder with the area of $396 \mathrm{~cm}^{2}$ was about $15 \%$ of that of copper at $5.1 \mathrm{~K}$. Further improvements in surface resistance and its reproducibility are necessary to fabricate a microwave high- $T_{c}$ cavity.

\section{Acknowledgements}

We would like to express our sincere thanks to Professor Hirotaka Sugawara, Director General of KEK, and Professor Tetsuji Nishikawa, the former Director General, for support of this experiment. Furthermore we would like to express our thanks to Professor Yoshitaka Kimura, Professor Koji Takata and Professor Emeritus Yuzo Kojima for their encouragement and discussion. 


\section{References}

[1] G. Müller: Proc. 4th Workshop of RF Superconductivity, Tsukuba, 1980, p.267.

[2] N. Klein, G. Müller and H. Piel: Appl. Phys. Lett. 54 (1989) 757.

[3] S. S. Laderman, R. C. Taber, R. D. Jacowitz, J. L. Moll, C. B. Eom, T. L. Hylton, A. F. Marshall, T. H. Geballe and M. R. Beasley: Phys. Rev. B 43 (1989) 2922.

[4] W. L. Holstein, L. A. Parisi, C. Wilker and R. B. Flippen: Appl. Phys. Lett. 60 (1992) 2014.

[5] N. McN. Alford, T. W. Button, M. J. Adams, S. Hedges, B. Nicholson and W. A. Phillips: Nature 349 (1991) 680.

[6] T. W. Button, N. McN. Alford, F. Wellhofer, T. C. Shields, J. S. Abell and M. Day: IEEE Trans. Magn. 27 (1991) 1434.

[7] T. W. Button and M. McN. Alford: Appl.Phys.Lett. 60 (1992) 1378.

[8] C. Uher: J. Supercond. 3 (1990) 337.

[9] C. L. Bohn, J. R. Delayen, U. Balachandran and M. T. Lanagan: Appl. Phys. Lett. 55 (1989) 304.

[10] D. W .Cooke, E. R. Gray, P. N. Arendt, G. A. Reeves, R. J. Houlton, N. E. Elliott and D. R. Brown: Appl. Phys. Lett. 56 (1990) 2147.

[11] D. W. Cooke, E. R. Gray, P. N. Arendt, B. L. Bennett, D. R. Brown, N. E. Elliott, A. J. Klapetzky, G. A. Reeves and A. M. Portis: J. Supercond. 3 (1990) 261.

[12] H. Piel, M. Hein, N. Klein, A. Michalke, G. Müller and L. Ponto: Physica C 153-155 (1988) 1604.

[13] H. Hein, E. Mahner, G. Müller, H. Piel, L. Ponto, M. Becks, U. Klein and M. Peiniger: Physica C 162-164 (1989) 111.

[14] M. Hein, G. Müller, H. Piel, L. Ponto, M. Becks, U. Klien and M. Peiniger: J. Appl. Phys.66 (1989) 5940.

[15] K. Tachikawa, I. Watanabe, S. Kosuge, M. Kabasawa, T. Suzuki, Y. Matsuda and Y. Shinbo: Appl. Phys. Lett. 52 (1988) 1011.

[16] K. Tachikawa, M. Ono, Y. Shinbo, T. Suzuki, M. Kabasawa and S. Kosuge: IEEE Trans. Magn. 25 (1989) 2029.

[17] W. T. Elam, J. P. Kirkland. R. A. Neiser and E. F. Skelton: Adv. Ceram. Mater. 2 (1987) 411.

[18] J. P. Kirkland, R. A. Neiser, H. Herman, W. T. Elam, S. Sampath, E. F. Skelton, D. Gansert and H. G. Wang: Adv. Ceram. Mater. 2 (1987) 401. 
[19] J. J. Cuomo, G. R. Guarnieri. S. A. Shivashankar, R. A. Roy, D. S. Yee and R. Rosenberg: Adv. Ceram. Mater. 2 (1987) 422.

[20] K. Tachikawa, Y. Shinbo, M. Ono, M. Kabasawa and S. Kosuge: Adv. Cryog. Eng. (Mater.) 36 (1990) 473.

[21] K. Tachikawa, Y. Shinbo, M. Ono, M. Kabasawa and S. Kosuge: Proc. 11th. Int. Conf. Magnet Technology, Tsukuba, 1989, p.1494.

[22] K. Asano and K. Yoshihara: Proc. 4th Workshop on RF Superconductivity, Tsukuba, 1989 , p.723.

[23] T. V. Duzer and C. W. Turner: Principles of Superconductive Devices and Circuits (Elsevier, North Holland, New York, 1981).

[24] D. R. Harshman, L. F. Schneemeyer, J. V. Waszczak, G. Aeppli, R. J. Cava, B.Batlogg and L. W. Rupp: Phys. Rev. B 39 (1989) 851.

[25] L. Krusin-Elbaum, R. L. Greene, F. Holtzberg, A. P. Malozemoff and Y. Yeshurun: Phys. Rev. Lett. 62 (1989) 217.

[26] T. L. Hylton, A. Kapitulnik and M. R. Beasley: Appl. Phys. Lett. 53 (1988) 1343.

[27] T. L. Hylton and M. R. Beasly: Phys. Rev. B 39 (1989) 9042.

[28] E. B. Sonin and A. K. Tagantsev: Phys. Lett. A 140 (1089) 127.

[29] J. S. Dugdale: Landolt-Boernstein Numerical Data and Functional Relationships in Science and Technology, eds. K. H. Hellwege and J. L. Olsen (Springer, Berlin, 1982), Vol.15, Subvol. a, p.31. 


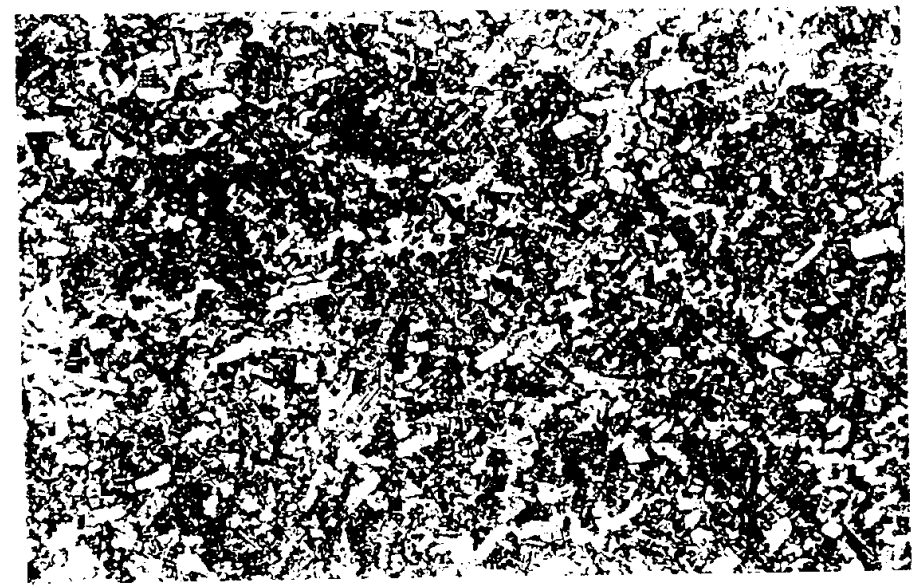

Fig. 1. Surface of the $\mathrm{YBaCuO}$ film sprayed onto nickel-buffered copper, observed using a polarized light microscope.

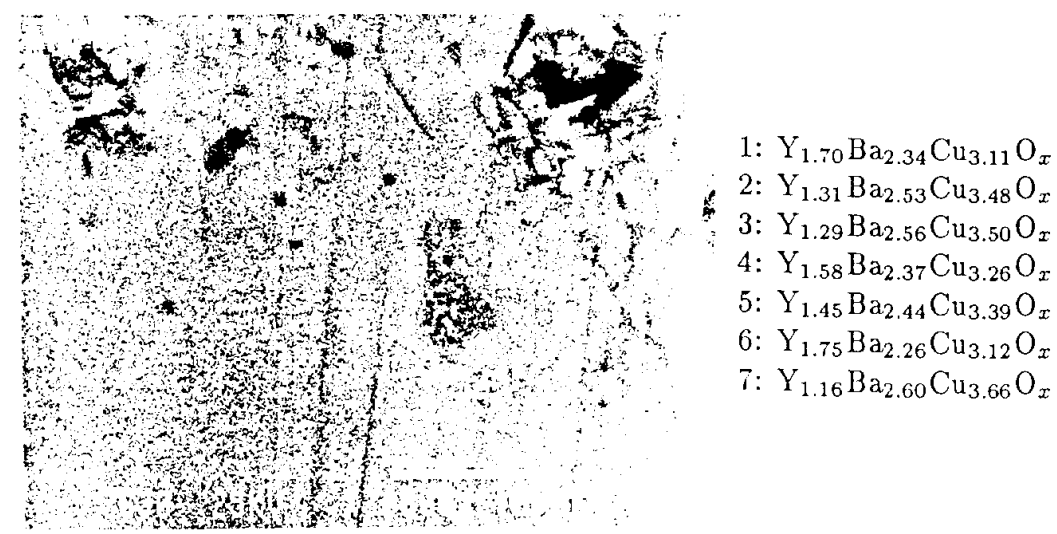

(a)
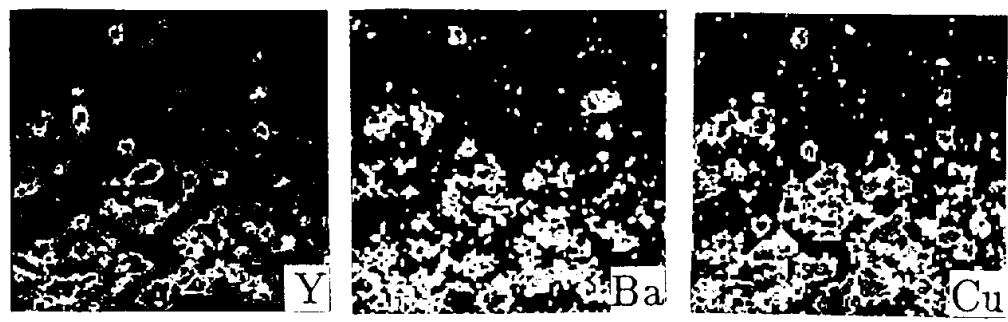

(b)

Fig. 2. Cross section of the oxide layer after annealing.

(a) SEM image at the cross section between the reacted layer (upper half of the figure) and layer I (lower half).

The chemical compositions at several points are shown to the right.

(b) EDX images showing the distribution of $\mathrm{Y}, \mathrm{Ba}$ and $\mathrm{Cu}$ in the upper middle sextant of the top picture. The content increases in the order of black, violet, blue, green, yellow and red. 


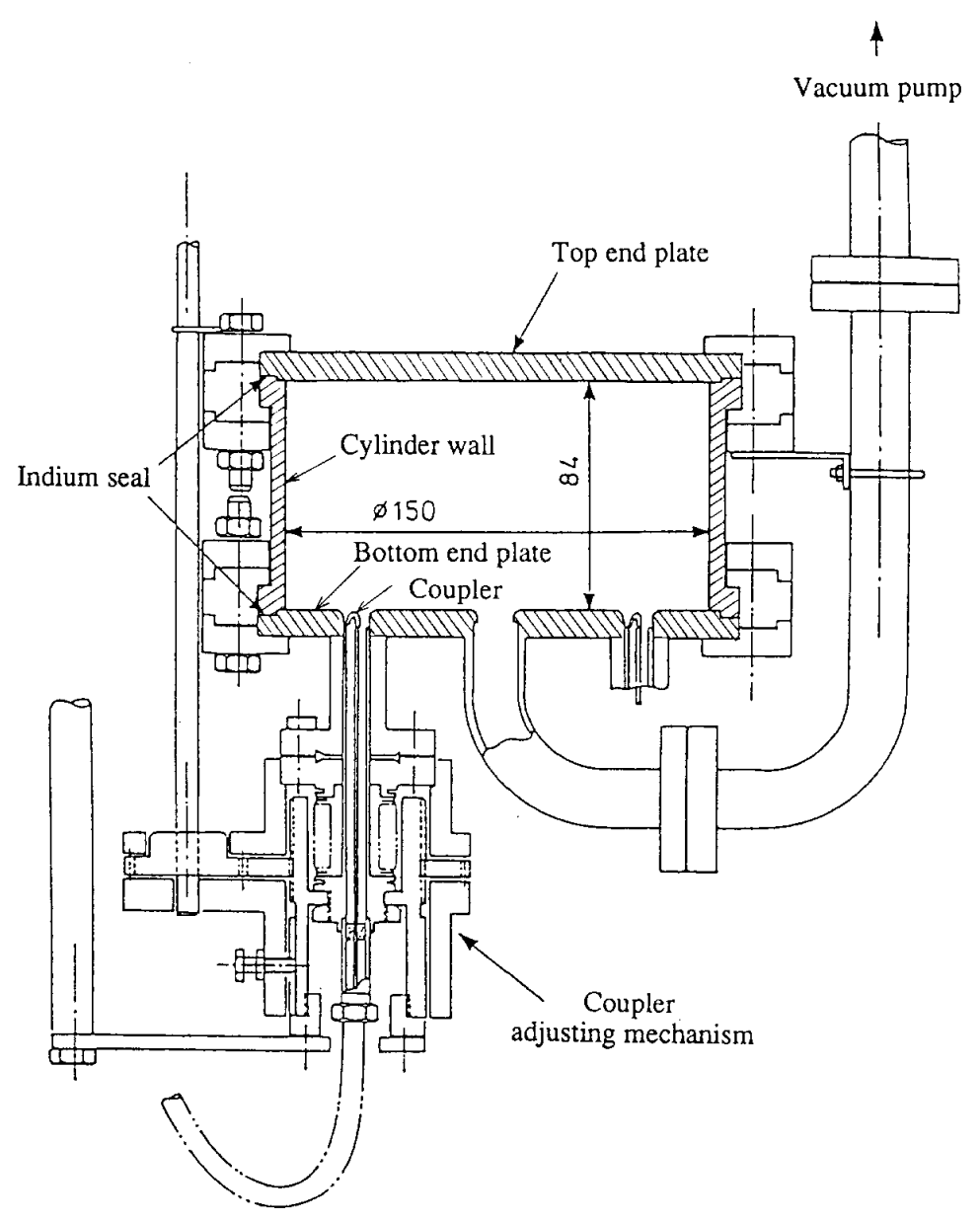

Fig. 3. Demountable cavity for measuring surface resistance.

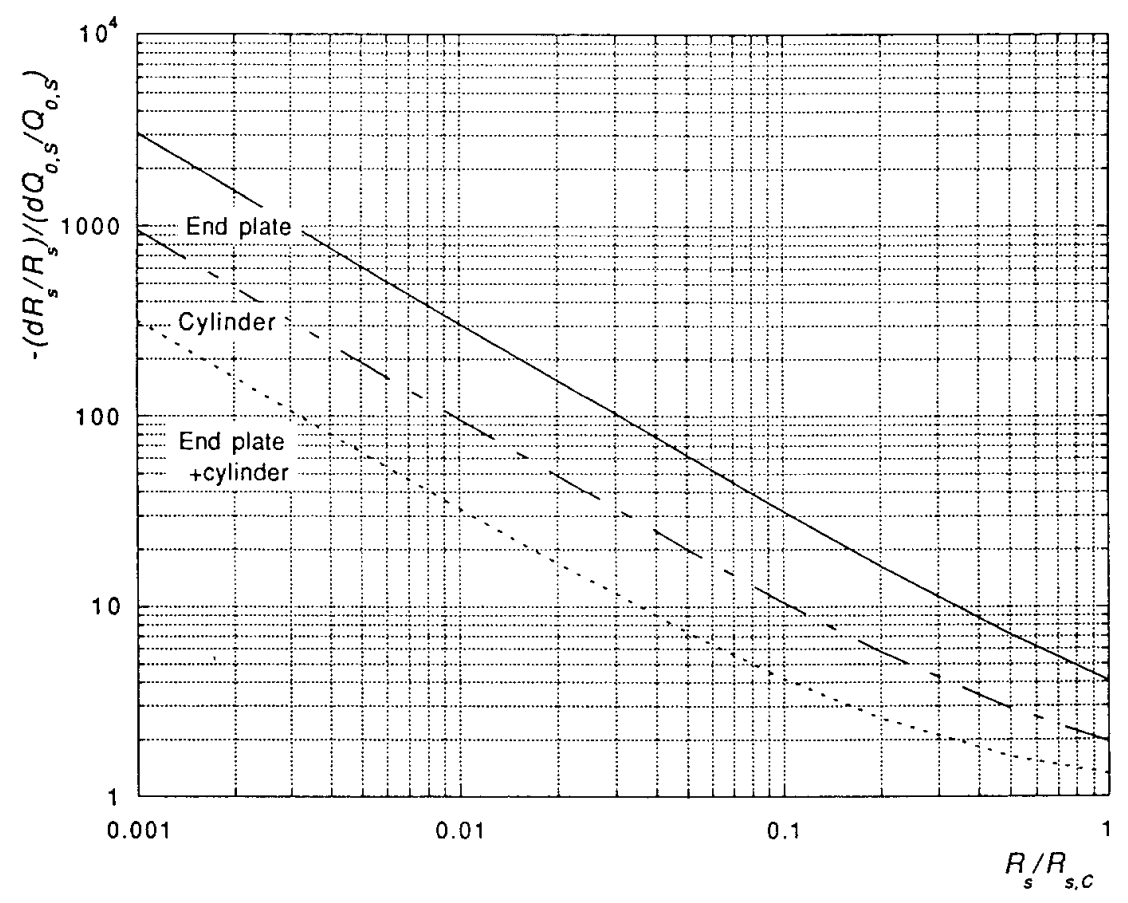

Fig. 4. Ratio of relative resistance variation to relative $Q_{0}$ variation as a function of the normalized surface resistance. 


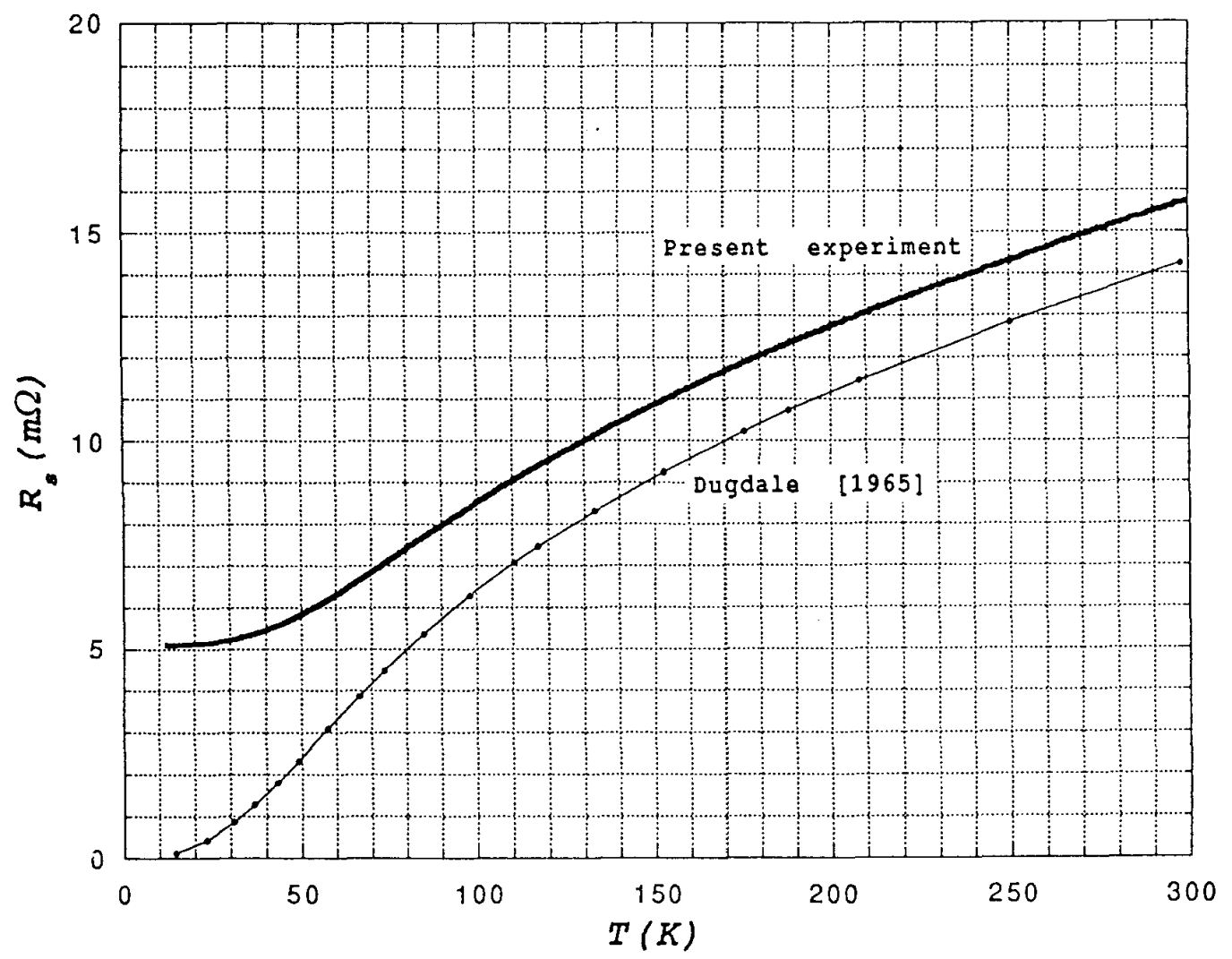

Fig. 5. Surface resistance of the $3 \mathrm{GHz}$ entire copper cavity as a function of temperature.

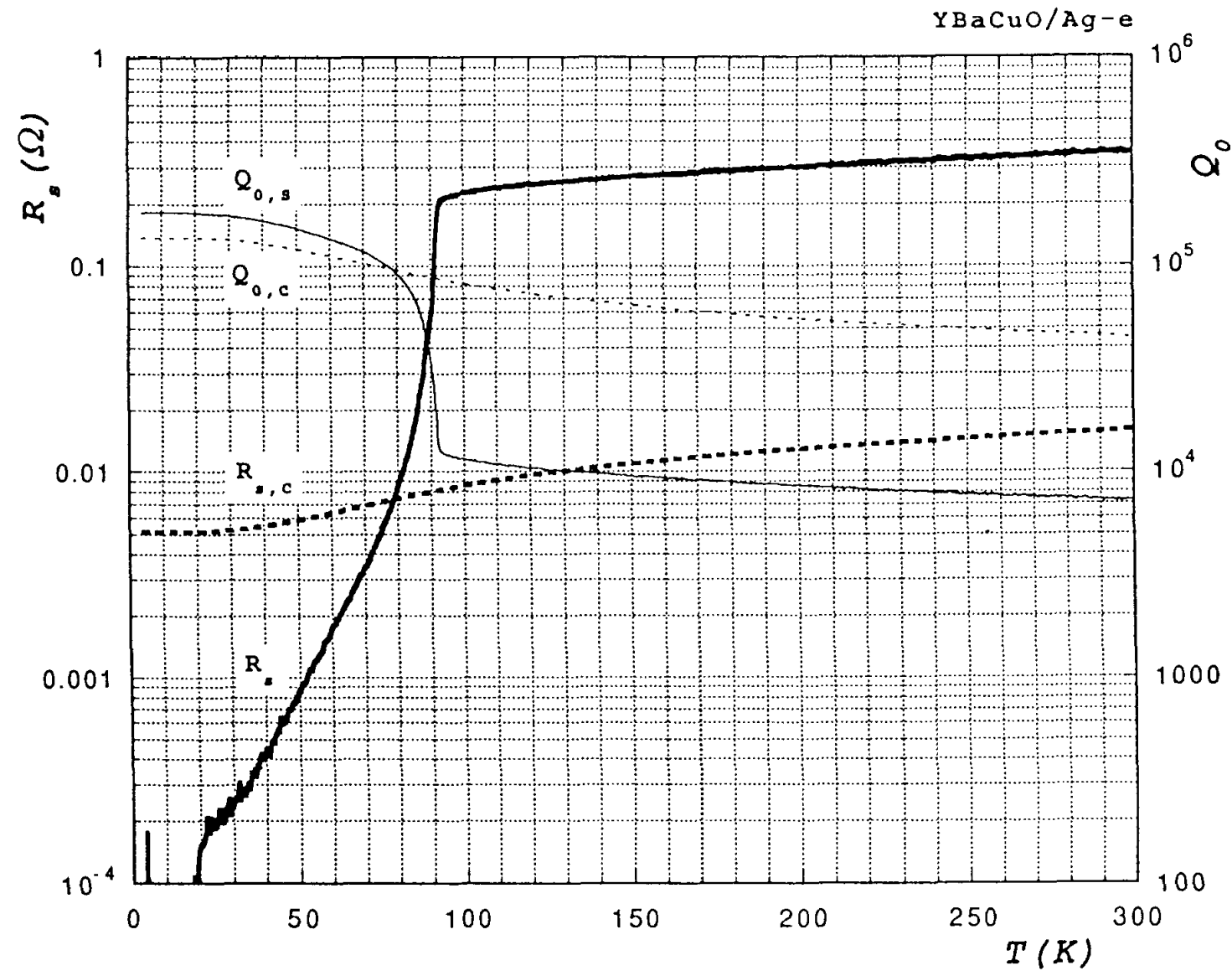

Fig. 6. Surface resistance and $Q_{0}$ value of $\mathrm{YBaCuO} / \mathrm{Ag}$-e as well as those of copper. 


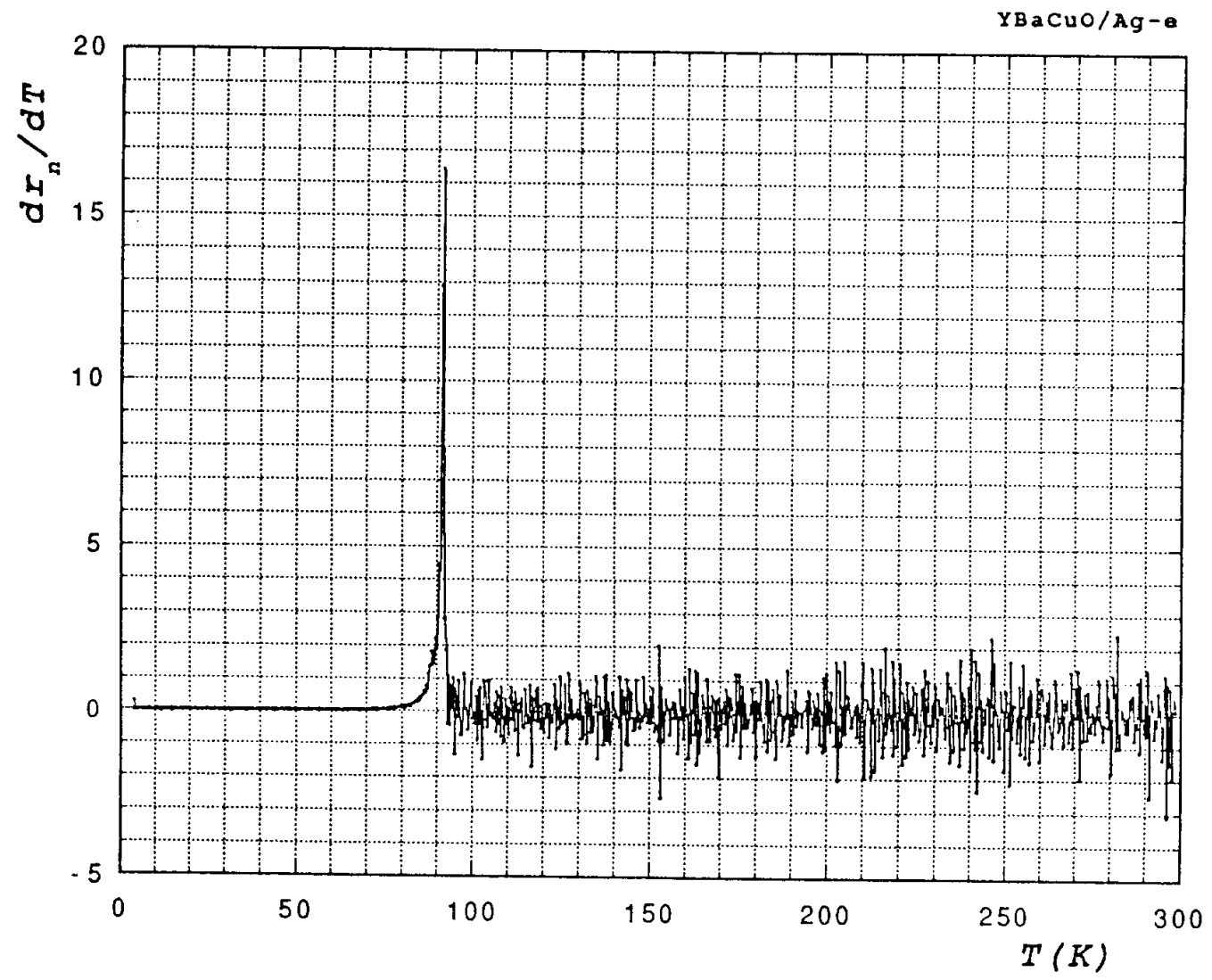

Fig. 7. Derivative of the normalized surface resistance, showing the onset transition temperature of $\mathrm{YBaCuO} / \mathrm{Ag}-\mathrm{e}$.

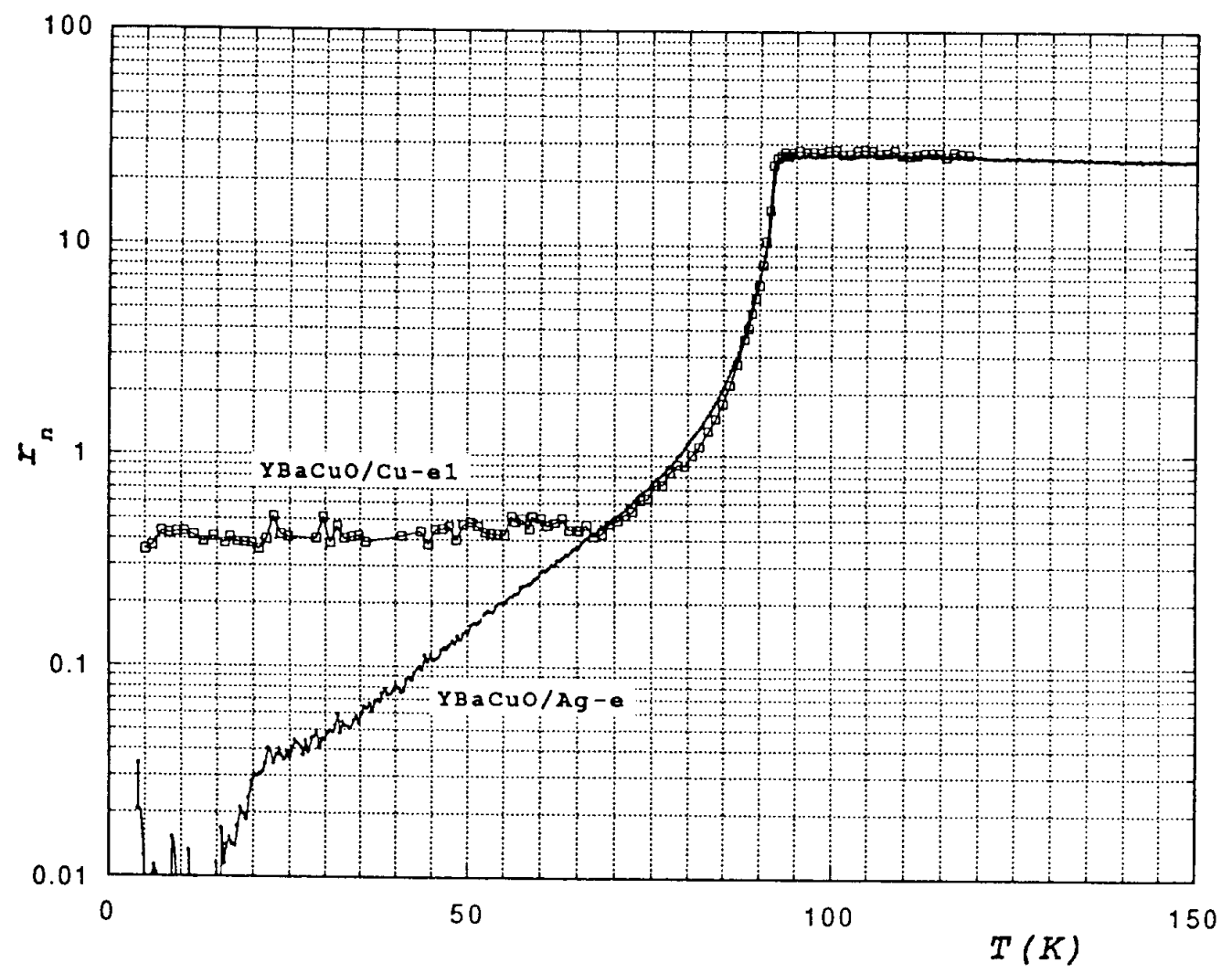

Fig. 8. Normalized surface resistance of $\mathrm{YBaCuO} / \mathrm{Cu}-\mathrm{el}$. 


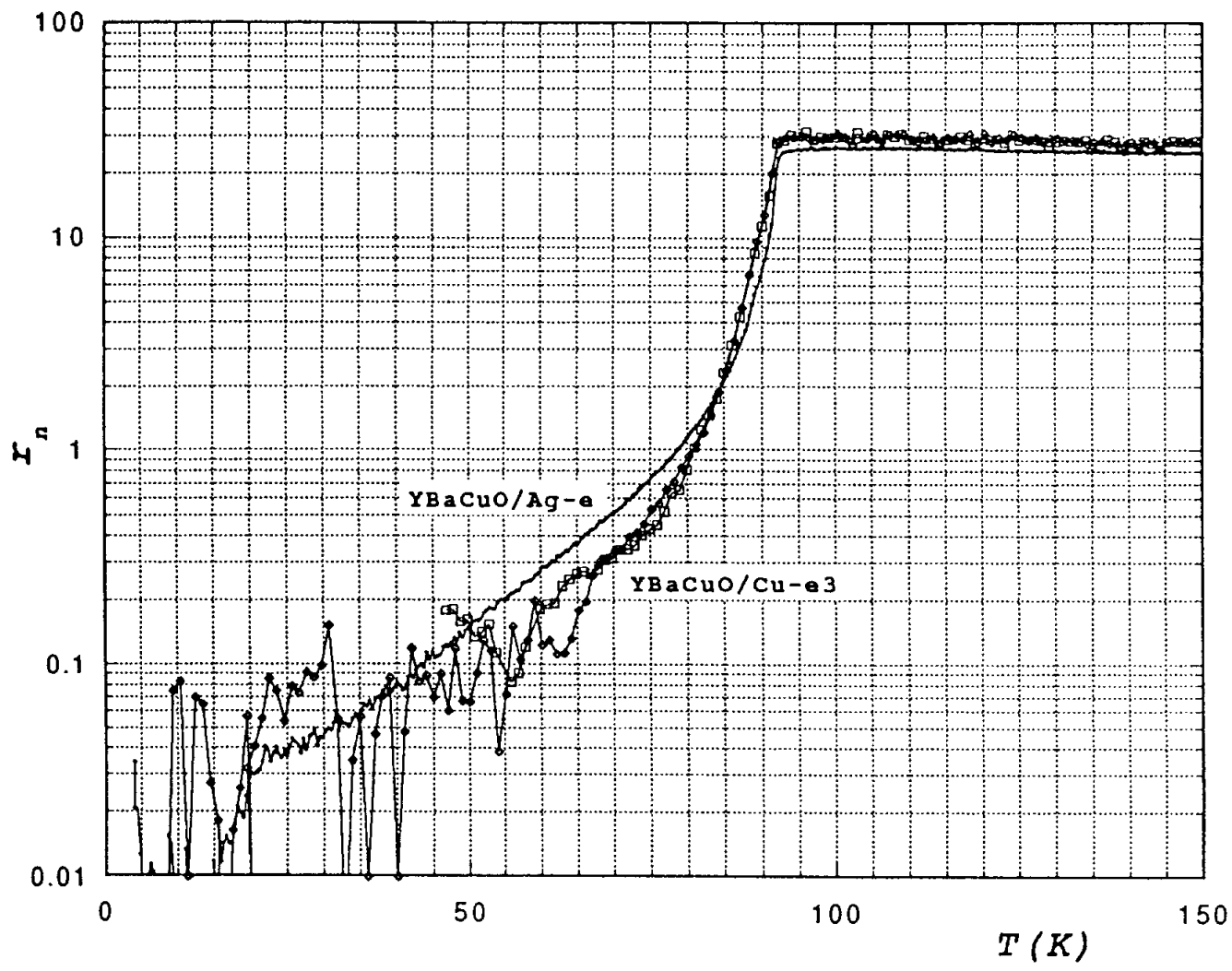

Fig. 9. Normalized surface resistance of $\mathrm{YBaCuO} / \mathrm{Cu}-\mathrm{e} 3$.

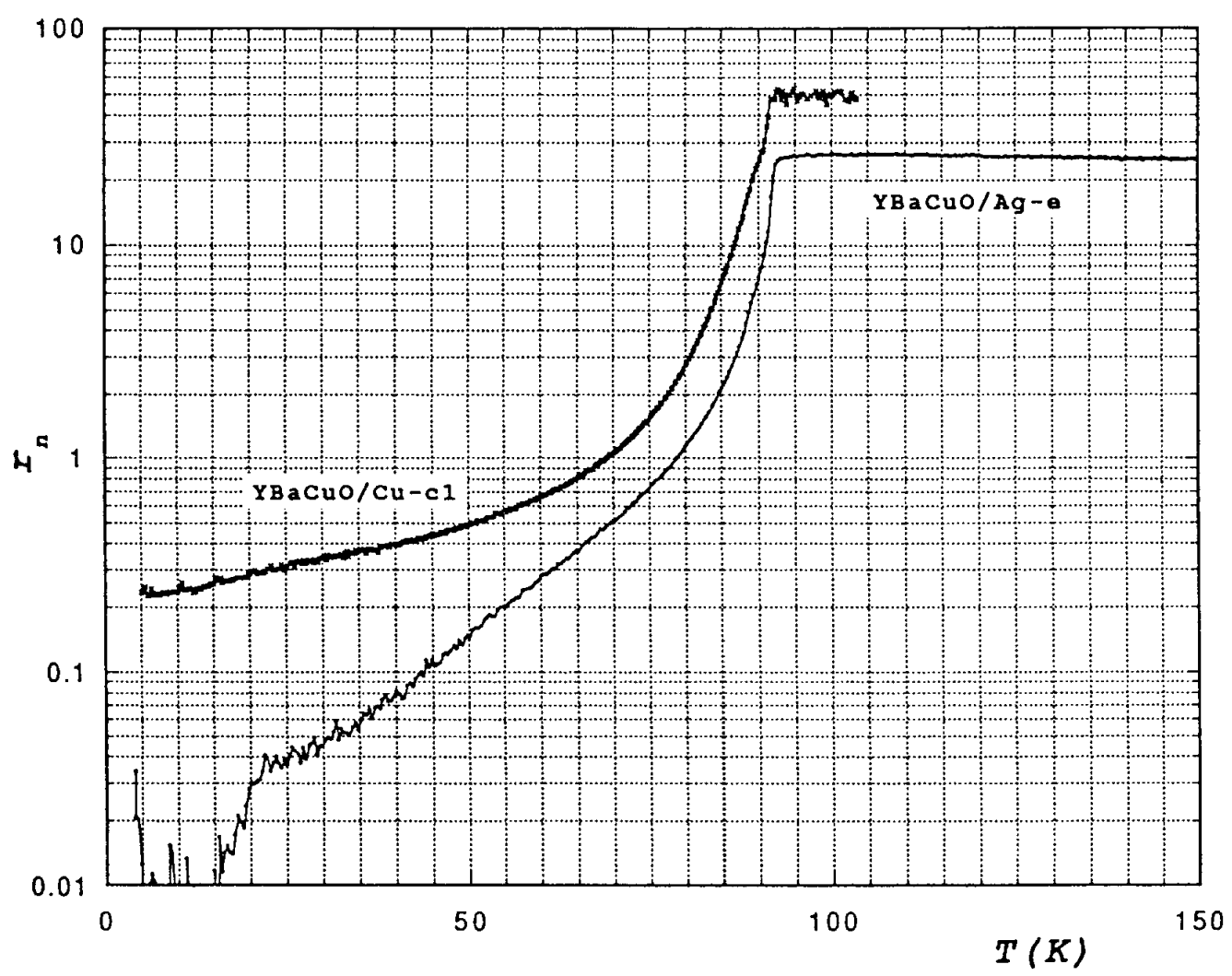

Fig. 10. Normalized surface resistance of $\mathrm{YBaCuO} / \mathrm{Cu}-\mathrm{cl}$. 